\title{
Behavioral Intention to Accept and Use Banking Service*
}

\author{
Nguyen Thi NGAN ${ }^{1}$, Bui Huy KHOI ${ }^{2}$
}

Received: August 01, 2020 Revised: September 06, 2020 Accepted: October 05, 2020

\begin{abstract}
Banking service is provided by a bank that allows its customers to conduct banking transactions and so the purpose of this study was to identify the factors that influenced the behavioral intention to accept and use banking services in Vietnam. The research methodology was implemented through two steps: qualitative research and quantitative research. Qualitative research was conducted with a sample of 30 people. Quantitative research was carried out as soon as the question was edited from the test results with a sample of 217 customers living in Ho Chi Minh City, Vietnam. The research model was proposed from the studies of the behavioral intentions to accept and use banking service. The reliability and validity of the scale were evaluated by Cronbach's Alpha, Average Variance Extracted (Pvc), and Composite Reliability (Pc). The model selection of AIC showed that the behavioral intention to accept and use banking service was impacted by four components. The outcomes showed that the model of research intended to accept and use banking services in Ho Chi Minh, Vietnam showing the effects of 4 scales is built as perceived ease of use, trust, social norm, and innovation about banking services.
\end{abstract}

Keywords: Banking Service. Consumer Behavior, Behavioral Intention, Social Norm, Technology Acceptance Model, Vietnam

JEL Classification Code: M31, M37, D7, C5

\section{Introduction}

Banking service is provided by a bank that allows its customers to conduct banking transactions (Le et al., 2020). Behavioral intention (BI) is described as a broad engagement of a client with a contemporary product or service that a person will consistently use in the future (Lai et al., 2019; Oliver, 2014). Jani and Han (2015), Kaur and Soch (2012) also expressed BI as the encouragement of clients, which includes their families and friends, to utilize their goods or services. The intention of consumers to continue utilizing the products or services for a long time; the willingness of

\footnotetext{
*Acknowledgements:

This research is funded by the Industrial University of Ho Chi Minh City, Vietnam

${ }^{1}$ First Author. Lecturer, Faculty of Business Administration, Industrial University of Ho Chi Minh City, Vietnam.

Email: nguyenthingan@iuh.edu.vn

${ }^{2}$ Corresponding Author. Lecturer, Faculty of Business Administration, Industrial University of Ho Chi Minh City, Vietnam [Postal Address: 218/23/8 Nguyen Duy Cung, Govap Dist, Ho Chi Minh City, 700000, Vietnam] Email: buihuykhoi@iuh.edu.vn

(C) Copyright: The Author(s)

This is an Open Access article distributed under the terms of the Creative Commons Attribution Non-Commercial License (https://creativecommons.org/licenses/by-nc/4.0/) which permits unrestricted non-commercial use, distribution, and reproduction in any medium, provided the original work is properly cited.
}

clients to pay a higher price for the goods and services they consistently use compared to people who use it irregularly (Lai et al., 2019). The study of consumer behavior is intended to explain the process of buying or not buying a commodity. The study of intention to accept and use the products and services is a research field on consumer behavior, and the researchers proved that the intention of shopping significantly affects the form of customers' shopping behavior. According to the studies in the past, the intention to accept and use a service is understood to be a motivation to act and decide about whether to use or not use a service in the future (Ajzen, 1991, 2005; Ajzen, 2010; Park et al., 2018; Venkatesh et al., 2003).

Buyer behavior has emerged as an important field of scientific research in the retailing industry and it is performed in various fields. In particular, the intention to accept and use the product/service by customers is always an essential research category in the area of consumer research. Intention to accept and use a product/service when it is attached to a specific context and situation has a lot of issues that need to be further studied and exposed. In this paper, besides directly delving into previous studies about the intention to accept and use a product/ services, this research not only aims to study categories in a single, discrete and independent way but also integrates various contents to build a more complete study about the impact of various factors in intention to accept and use a product/service. 
This study has been conducted in the context of clients from the rural areas and the product used for this study is the banking services provided in the rural area in Vietnam. Furthermore, relationships among various factors became apparent while studying the impact of information on the services in relation to these factors such as perceived usefulness, perceived ease of use, trust, innovation, and social norm on the intention to accept and use banking services.

There has been considerable of economic development and progress in Vietnam, especially in Ho Chi Minh City. The country and the city, in particular, have gone through globalization and in the process, there has been a growing demand for banking services both in terms of the quality and the quantity. Although the need for banking services is increasing, many customers in this area have yet to accept and use banking services, as a result, banking operations in rural areas have not made much progress as per expectations. This situation related to the use of banking services requires a deep study to understand the determinants which affect the intention to use banking services in Ho Chi Minh City, Vietnam.

There have been a few research conducted around the world including Vietnam and the results have been analyzed by the authors of this paper. The results gathered from the data shows the real performance of commercial banks along with factors affecting the intention to use banking services in rural areas. It is necessary for the banks to recognize factors affecting intention to use banking services of customers in their area and should be the basis for analysis, reviews, as well as the selective application of these solutions to other rural areas in Vietnam. While evaluating intention to accept and use rural banking services is reviewed in relation to the variable which is 'innovation about the service', then exploring the impact made by these factors: perceived usefulness, perceived ease of use, trust, innovation, and social norm becomes important.

With the above analysis, this paper reveals the determinants affecting the intention to accept and use banking services in Ho Chi Minh City, Vietnam.

\section{Literature Review}

\subsection{Behavioral Intention (BI)}

Individually considered, the intention is based on an individual's attitude toward the behavior, perceived norms, and $\mathrm{PBC}$, with each predictor, weighted for its importance with the behavior and population under assessment (I Ajzen, 2010). The stronger an individual's intention to perform a behavior, the more likely it will be performed. Ajzen (2010) described the behavior as the observable response in a given situation to a specific target. More specifically, the behavior is a function of compatible intentions and perceptions of behavioral control. When behaviors pose no serious problems of control, they can be predicted from intentions with considerable accuracy (Icek
Ajzen, 1991). Behavioral intention can be understood with how much a consumer uses technology for banking. Interest in behavior can be viewed from the level of technology use so it can be derived from the attitude and attention to technology, the motivation to keep utilizing such technology, as well as motivating other users (Muchran and Ahmar, 2019).

Being aware of the usefulness, perceived ease of use of a product/services/bank's new technology is said to be one of the fundamental determinants that impact attitudes and behavior to accept and use banking products and services. Many studies are using the Technology Acceptance Model, Theory of Reasoned Action, and combined with other models that proved this idea (Gunawardena et al., 2018; Muchran and Ahmar, 2019; Park et al., 2018; Yu et al., 2018). Besides, the influence of social factors on the intention to accept and use banking service has been tested in many models. The influence of social impact shows the impact of the community on the intention to perform a specific behavior of people. The behavior of a consumer is also subject to the impact of social factors such as family, the role and social status, and the reference group.

Belief is a very important element in many business relationships to decide the development of many enterprises and the social order. The study of Jaruwachirathanakul and Fink, (2005) showed that besides concerns about losing money, customers are also very concerned about information security, and invasion on their privacy. For decades, the research is science has displayed that customers get interested and active of the suppliers bring innovation and creativity in their products and services. The researchers extended and integrated models and conducted more studies to learn more about the innovation factor with relation to customers accessing and accepting the use of a new product especially in the field of using information technology services.

In the development process of the research about the intention to accept and use services of customers, researchers interested in communication and information factors as an independent variable, intermediate, or even as dependent variables that impact the intention to accept and use services of customers. Extensive studies in the past decades provided evidence of the considerable impact of communication factors affecting customers' intention to use services.

Although there are a few studies on factors affecting intention to use banking services in rural areas all over the world and Vietnam, the above theories along with empirical evidence in different fields will have a contribution to building the research model and assumptions in the context of rural areas and rural areas of Vietnam in particular.

\subsection{Perceived Usefulness (PU)}

Perceived Usefulness (PU) considers as the degree to which a person believes that using a particular system would 
enhance his or her job performance (Phan et al., 2019). According to Lazim et al. (2018), perceived usefulness is defined as a measure by which the use of technology is believed to provide benefits to the person using it, and the perception of usefulness as the subjective ability of future users where using a specific application system will improve performance in the organizational context. Usability perception is a level where one believes that the use of a particular technology will provide benefits or provide a positive impact that will be obtained when using the technology (Muchran and Ahmar, 2019). Previous research in the context of perceived ease of use provides evidence of the significant and positive effect on the intention to use (De Leon, 2019; Kumar et al., 2017). Perceived usefulness is the subjective understanding of users when using the services of a special application method, and their job administration will develop (Davis et al., 1989). Many empirical studies demonstrated that bringing awareness related to the usefulness and ease of use related factors enhanced the intention to use a product/service/technology (Dasgupta et al., 2011; Sripalawat et al., 2011; Venkatesh and Zhang, 2010). Kumar et al. (Kumar et al., 2017) investigated the factors influencing management students in India on their intention to use mobile banking and found that perceived ease of use has a significant influence on intention.

\subsection{Perceived Ease to Use (PEU)}

According to Lazim et al. (2018), perceived ease of use is determined as a supposition where it is understood that a person is able to understand and use a computer with ease. Meanwhile, according to Muchran and Ahmar (2019), perception of ease is interpreted as the extent to which a person understands that by utilizing technology he will be free of a business so that if a person believes that the information system is easy to use then he will use it and vice versa. The perception of the ease in using services is the degree to which users perceive the difficulty or ease to understand as to how to use products and services at their disposal (Muchran and Ahmar, 2019). Many empirical studies showed that perceived usefulness and perceived ease to use are related factors in the context of intention to use a product/service/technology which can be derived from the empirical evidence from various contexts above (Dasgupta et al., 2011; Sripalawat et al., 2011; Venkatesh and Zhang, 2010).

\subsection{Trust (TR)}

De Leon (2019) Trust propensity is a person's tendency to depend on others in different circumstances. When individuals have no experience in mobile banking, his or her initial trust in the said service is, therefore, expected to be a function of his/her propensity of trust (De Leon, 2019). Foon and Fah (2011) believed that customer's trust is the most important related factor in their intention to use products, services, and technology. Based on the studies of Kumar et al. (2017) and De Leon (2019), trust propensity is significantly associated with using mobile banking and strongly affects the intention to use mobile banking.

\subsection{Social Norm (SN)}

Social norms, subjective norms, or normative pressures are the terms used for social influences (De Leon, 2019; Makanyeza, 2017). Venkatesh et al. (2003) stated that the social norm is the degree to which an individual is aware of their important people, and other people think that they should use some products. The research of previous authors concluded that social norm has a relative impact on customers' intention to use (Foon and Fah, 2011; Sripalawat et al., 2011; Venkatesh et al., 2003; Venkatesh and Zhang, 2010). Individuals are likely to adopt the services if they deem that important people in their lives would agree on using mobile banking services. Several researchers found that individual intention to use mobile banking was significantly affected by people surrounding them (De Leon, 2019; Kumar et al., 2017; Makanyeza, 2017; Sharma et al., 2017). Singh and Srivastava (2018) revealed that individual decisions to adopt mobile commerce services were influenced by friends and family members and argued that these users are part of the social network, not just technology users. As concluded in the study of Makayeza (Makanyeza, 2017), social influence has a positive effect on behavioral intention to adopt mobile banking services.

\subsection{Innovation (IN)}

The diffusion of innovation theory concerns managerial factors, which is "manager's attitude" toward innovation (Nguyen and Le, 2020). Steenkamp and Gielens (2003) defined innovation as the tendency to buy fancy new and different products. Customers' innovation is shown through the desire to search for information about the product. Steenkamp and Gielens (2003), Im et al. (2007) stated that innovation is one of the important factors for interest in new products and services. Research of Alalwan Alalwan (2020) also confirmed innovative factor has a related impact on the customers' intention to use of products and services.

In this paper, we have designed an empirical study in the context of intention to accept and use the products and services in Vietnam to examine factors as below function:

$$
\mathrm{BI}=\beta_{0}+\beta_{1} \mathrm{PU}+\beta_{2} \mathrm{PEU}+\beta_{3} \mathrm{TR}+\beta_{4} \mathrm{SN}+\beta_{5} \mathrm{IN}+\mathrm{e}
$$

Code: Innovation (IN), Social norm (SN), Trust (TR), Perceived ease to use (PEU), Perceived usefulness (PU), Behavioral intention (BI). 


\section{Research Methods and Materials}

\subsection{Research Approach}

An overview of the research methods used to collect and analyze the data was briefly discussed. In this research, a survey with a questionnaire was used to collect data. The questionnaire was made in English and then translated into Vietnamese because all of the respondents were Vietnamese. The research methodology was implemented through two steps: qualitative research and quantitative research. Qualitative research was conducted with a sample of 30 people. Quantitative research was carried out as soon as the question was edited from the test results with a sample of 217 people. According to Hair

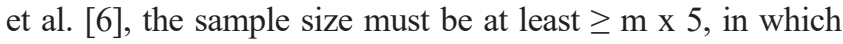
$\mathrm{m}$ is the number of observed variables. So, with 26 items observed in this study, the sample size should be at least $\geq 150$. Therefore, 217 people are surveyed by the face-to-face method in Ho Chi Minh City, Vietnam. The questionnaire answered by respondents is the main tool to collect data. The survey was conducted in the year 2019. The questionnaire contained questions about the position of the factors that influenced the behavioral intention in Vietnam. A Likert-scale type questionnaire was used to detect those factors measured from (1) "strongly disagree" to (5) "strongly agree".

\subsection{Blinding}

All study personnel and participants were blinded for the duration of the study. No one from the outside world had any contact with the study participants.

\subsection{Datasets}

We validate our model on three standard datasets for the behavioral intention to accept and use banking service in Vietnam: Smartpls, Stata, and R. Dataset has nine variables: eight independent variables and one variable. There are 217 observations and 26 items in a dataset. Smartpls was used for advanced analysis, Stata for Lasso regression, and R for model choice.

\subsection{Data Analysis}

Data processing and statistical analysis software are used by SmartPLS and R software. The scale's reliability and validity were checked by Cronbach's alpha $(\alpha)$, average variance extracted $\left(\rho_{v c}\right)$, and composite reliability (Pc). AIC was utilized to choose the best model. Cronbach's alpha coefficient higher than 0.6 would guarantee the scale's reliability (Nunnally and Bernstein, 1994). Pc is better than 0.6 and $\rho_{v c}$ must be greater than 0.5 . AIC was utilized to choose the best model by R software. AIC (Akaike's Information Criteria) was used for model selection in the theoretical framework. AIC method can handle many independent variables, even when multicollinearity exists. AIC can be implemented as a regression model, predicting one or more dependent variables from a set of one or more independent.

\section{Results and Discussion}

\subsection{Reliability and Validity}

In the studious model, convergent validity was examined through $\rho_{c}$ or Cronbach's alpha. $\rho_{v}$ and $\rho_{v c}$ were the measures of reliability since Cronbach's alpha often undervalues the scale reliability (Hengky Latan and Richard Noonan, 2017). The heterotrait-monotrait ratio of correlations (HTMT) was contracted to confirm data validity. Nevertheless, according to Hair et al. (Hair et al., 2017; Hair Jr et al., 2016), Cronbach's alpha and Pc values should be higher than 0.60 , and $\rho_{v c}$ the index should be higher than 0.50 for the validation of construct reliability. Alternatively, in terms of construct validity, follow to Hair et al. (Hair et al., 2017; Hair Jr et al., 2016), HTMT values should be less than 1.0 in Table 2 . The result of the construct's reliability and validity are shown in Table 1 and 2 .

Table 1: Reliability

\begin{tabular}{|l|c|c|c|c|c|}
\hline Factor & Cronbach's Alpha & rho_A & Pc & Pvc & Decision \\
\hline BI & 0.794 & 0.801 & 0.867 & 0.620 & Accepted \\
\hline IN & 0.551 & 0.630 & 0.716 & 0.352 & Accepted \\
\hline PEU & 0.825 & 0.829 & 0.883 & 0.654 & Accepted \\
\hline PU & 0.656 & 0.657 & 0.784 & 0.424 & Accepted \\
\hline SN & 0.630 & 0.958 & 0.703 & 0.351 & Accepted \\
\hline TR & 0.516 & 0.567 & 0.757 & 0.517 & Accepted \\
\hline
\end{tabular}

$$
\alpha=\frac{k}{k-1}\left[1-\frac{\sum \sigma^{2}\left(x_{i}\right)}{\sigma_{x}^{2}}\right], \rho_{c}=\frac{\left(\sum_{i=1}^{\rho} \lambda_{i}\right)^{2}}{\left(\sum_{i=1}^{\rho} \lambda_{i}\right)^{2}+\sum_{i=1}^{\rho}\left(1-\lambda_{i}^{2}\right)} \text {, and } \rho_{v c}=\frac{\sum_{i=1}^{\rho} \lambda_{i}^{2}}{\sum_{i=1}^{\rho} \lambda_{i}^{2}+\sum_{i=1}^{\rho}\left(1-\lambda_{i}^{2}\right)}
$$


This demonstrated that this model was internally logical. To investigate if these indicators for factors demonstrate converging validity, Cronbach's alpha was calculated. From 1 , it could be recognized that all the factors are reliable $(\mathrm{Pc}$, Cronbach's alpha $>0.60$ ), rho_A, and Pvc $>0.5$ (Wong, 2013). The factors $\mathrm{IN}$ and $\mathrm{SN}_{\bar{N}}$ had $\mathrm{Pvc}<0.5$, but other standards are accepted (see Table 1).

The results in Figure 1 explicated that the model fits with the analysis data (Wong, 2013). Five factors, about 52.4\%, modified the behavioral intention.

\subsection{Model Choice}

The lasso finds the solution to the optimization problem (Hastie et al., 2015), so it could be useful for designing algorithms for finding its solutions (Hastie et al., 2017; Hastie et al., 2015). We conducted two steps for Lasso regression in Table 3 and AIC for model choice in Table 4.

Akaike's Information Criteria (AIC) was used on the theoretical framework. AIC method could handle many independent variables, even when multicollinearity exists. AIC could be implemented as a regression model, predicting one or more dependent variables from a set of one or more independent variables, or it could be implemented as a path model.

AIC results in Table 4 showed that model 2 was the best. The behavioral intention to accept and use banking service was affected by two factors. In the AIC analysis in Table 4 , the variables associated with the behavioral intention to accept and use banking service. The most important factor for the behavioral intention to accept and use banking service was Trust (TR) with the Beta equals to 0.53641 with the function as follows.
Table 2: Validity

\begin{tabular}{|l|c|c|c|c|c|}
\hline Constructs & BI & IN & PEU & PU & SN \\
\hline IN & 0.770 & & & & \\
\hline PEU & 0.673 & 0.787 & & & \\
\hline PU & 0.728 & 0.813 & 1.026 & & \\
\hline SN & 0.388 & 0.605 & 0.336 & 0.680 & \\
\hline TR & 0.897 & 0.968 & 0.496 & 0.603 & 0.315 \\
\hline
\end{tabular}

Table 3: Lasso regression

\begin{tabular}{|l|c|c|}
\hline Selected & Lasso & Post-est OLS \\
\hline PU & 0.1140631 & 0.11402 \\
\hline PEU & 0.3049153 & 0.3116188 \\
\hline TR & 0.5110411 & 0.5201741 \\
\hline SN & 0.0769513 & 0.084405 \\
\hline IN & 0.0987523 & 0.1001877 \\
\hline cons & 0.7833645 & 0.4820458 \\
\hline
\end{tabular}

Table 4: Akaike's Information Criteria

\begin{tabular}{|l|l|c|}
\hline Unit & \multicolumn{1}{|c|}{ Model } & AIC \\
\hline 1 & $\mathrm{BI} \sim \mathrm{PU}+\mathrm{PEU}+\mathrm{TR}+\mathrm{SN}+\mathrm{IN}$ & 203.52 \\
\hline 2 & $\mathrm{BI} \sim \mathrm{PEU}+\mathrm{TR}+\mathrm{SN}+\mathrm{IN}$ & 203.41 \\
\hline
\end{tabular}

$A I C=-2 \log L+2 . d$

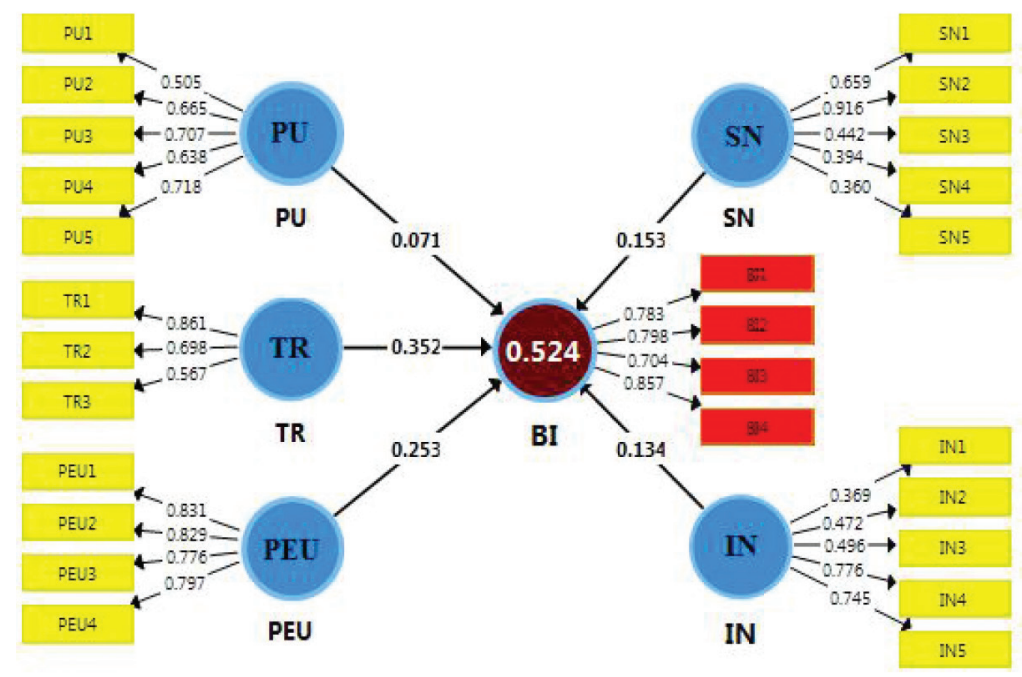

Figure 1: The SEM model 


$$
\begin{aligned}
\mathrm{BI}= & 0.69759+0.39307 \mathrm{PEU}+0.53641 \mathrm{TR}+0.11303 \mathrm{SN} \\
& +0.09942 \mathrm{IN}
\end{aligned}
$$

Code: Social norm (SN), Social norm (SN), Trust (TR), Perceived ease to use (PEU), Behavioral intention (BI).

\subsection{Discussion}

All measures, including perceived usefulness, perceived ease to use, trust, innovation, social norm about banking service after being evaluated by alpha Cronbach's, shows good results. Because scale indicates a focusing of comments fulfilled with the Cronbach's alpha coefficient $>0.6$ levels of acceptance popular and the Pc, rho_A, and Pvc $>0.5$, this is the reliability scale. By analyzing lasso regression, study models the intention to admit and use banking services in Vietnam shows the outcomes of 4 scales: perceived ease to use, trust, social norm, and innovation about banking services, explains $52.4 \%$ of the variability of the intention to accept and use banking products. The scale was chosen for variables in the model to guarantee the elements and is used in subsequent analysis. With those analyses above, this paper indicates the determinants affecting the intention to accept and use banking services in Ho Chi Minh City, Vietnam.

\section{Conclusions}

\subsection{Conclusion}

In formal research, with the analysis sample is 217 units, empirical research was using Smartpls, Stata, and R software to carry to determine scale options in the proposed model research to guarantee that high reliability is achieved in the standards of research and testing. The outcomes showed that the model of research intended to accept and use banking services in Ho Chi Minh, Vietnam showing the effects of 4 scales is built as perceived ease of use, trust, social norm, and innovation about banking services.

The influence of factors which affects intention to accept and use banking services in Vietnam was posting correlated by the Beta coefficient of the accredited independent variables in the model are $>0$. Following that, when these factors increased, the intention to accept and use banking services in Vietnam is also improved. The influence level of each factor is different. In circumstantial, trust is the strongest impact determinant on the intention to accept and use banking services in Vietnam. The Beta coefficient is 0.53641 . Consequently, the more clients believed in the safety and the security of banking services, the more likely they were to improve acceptance and increase their usage of banking services. Next, perceived ease of use is the weakest influence determinant to the intention to believe and use the banking services. The Beta coefficient is 0.39307 .

This paper was done to help bank managers identify several determinants concerning the intention to accept and use banking services in Vietnam. From there, they are allowing bank managers to develop policies to develop products and services to accommodate the field.

\subsection{Recommendations}

As considered, the intention to accept and use banking services is influenced by perceived ease to use, perceived usefulness, creativity, innovation, and social norm about service. To increase the intention to accept and use banking services as the basic criteria for increasing the use of banking services, the banks need to control the influence of the above factors.

The analysis results show determinants that most impact the intention to use banking products and services. It can also be easily found in the belief is a value that people are driven to, especially in the field of currency trading-services sector which is invisible and very sensitive and pertains to the psychology of the people who want to ensure the safety of their money. In banking services, there are distinct features: the poorer residents generally lack information and have low income therefore they are more inclined to guarantee safety of the finances. Therefore if the banks want that their clients trust them and use the banking services, the banks should implement following measures: completing banking transactions correctly, fully and promptly settle any claims by the clients, ensuring the safety of customer's information, being highly responsible in the process of implementing requirements of clients, timely handling of risks if it happens to any of their clients, expressing the positive things while offering the banking services, and building risk prevention measures for banking services to guarantee safety to the users

Building products that meet the demands and create profits for the user: focus on lending products to guarantee capital for economic growth. Increasing payment operations that do not use cash matches the demand for sale, exchange, and trading. Diversified financial services such as financial leasing, financial advice can be given to create a favorable environment for household business in this area, to find out and create new opportunities in the business, learning the characteristics of the culture of the area, learning and understanding the age of each group of people to build the right products; the bank should also be concerned about the difference in different cultures of different regions to determine how to approach and handle the day to day banking operations. 


\subsection{Further Research Suggestion}

This study was initially done to determine the factors affecting the intention to use banking services in Vietnam, which assessed the impact of each factor on the intention to use banking services in Vietnam. However, research results still have some restrictions and opened up the way forward for more research in the area:

First, current samples used and studied were small in scope and scale and was collected from the rural areas outside Ho Chi Minh City. So, to be able to assess more precisely the impact of these factors on the intention to use banking services in Vietnam, there needs to be an expansion in the size and scope of the study sample.

Second, regardless of studied factors such as perceived ease to use, trust, social norm, and innovation, there could be other factors that also affect the intention to use banking services. The next research can edit and add to the more comprehensive studies that intend to use banking services in rural areas and suburbs.

Third, besides, in other studies there was focus on the impact of the demographic characteristics of consumers to accept and use new products. In this study, the authors did not analyze the impact of demographic variables intention to accept and use banking services in rural areas and suburbs. Perhaps, this will be the author's next research in the future.

\section{References}

Ajzen, I. (1991). The theory of planned behavior. Organizational Behavior and Human Decision Processes, 50(2), 179-211.

Ajzen, I. (2005). Attitudes, personality, and behavior. London, UK: McGraw-Hill Education.

Ajzen, I. (2010). Constructing a theory of planned behavior questionnaire. Retrieved from: http://www.people.umass. edu/ aizen/pdf/tpb. measurement. pdf.

Alalwan, A. A. (2020). Mobile food ordering apps: An empirical study of the factors affecting customer e-satisfaction and continued intention to reuse. International Journal of Information Management, 50, 28-44.

Dasgupta, S., Paul, R., \& Fuloria, S. (2011). Factors affecting behavioral intentions towards mobile banking usage: Empirical evidence from India. Romanian Journal of Marketing, 6(1).

Davis, F. D., Bagozzi, R. P., \& Warshaw, P. R. (1989). User acceptance of computer technology: A comparison of two theoretical models. Management Science, 35(8), 982-1003.

De Leon, M. V. (2019). Factors influencing behavioural intention to use mobile banking among retail banking clients. Jurnal Studi Komunikasi, 3(2), 118-137.

Foon, Y. S., \& Fah, B. C. Y. (2011). Internet banking adoption in Kuala Lumpur: An application of UTAUT model. International Journal of Business and Management, 6(4), 161.
Gunawardena, L., Hemachandra, D., \& Kodithuwakku, S. S. (2018). Career Intention of Undergraduate Students: An Application of Theory of Planned Behavior. IUP Journal of Entrepreneurship Development, 15(1), 7-27.

Hair, J. F., Hult, G. T. M., Ringle, C. M., Sarstedt, M., \& Thiele, K. O. (2017). Mirror, mirror on the wall: a comparative evaluation of composite-based structural equation modeling methods. Journal of the Academy of Marketing Science, 45, 616-632. https://doi.org/10.1007/s11747-017-0517-x

Hair Jr, J. F., Hult, G. T. M., Ringle, C., \& Sarstedt, M. (2016). A primer on partial least squares structural equation modeling (PLS-SEM). Los Angeles, CA: Sage Publications.

Hastie, T., Tibshirani, R., \& Friedman, J. (2017). The elements of statistical learning: data mining, inference and prediction (2nd ed.). New York, NY: Springer.

Hastie, T., Tibshirani, R., \& Wainwright, M. (2015). Statistical learning with sparsity: the lasso and generalizations. Boca Raton, FL: Chapman and Hall/CRC.

Hengky Latan, \& Richard Noonan. (2017). Partial Least Squares Path Modeling: Basic Concepts, Methodological Issues and Applications. New York, NY: Springer.

Im, S., Mason, C. H., \& Houston, M. B. (2007). Does innate consumer innovativeness relate to new product/service adoption behavior?: The intervening role of social learning via vicarious innovativeness. Journal of the Academy of Marketing Science, 35(1), 63-75.

Jani, D., \& Han, H. (2015). Influence of environmental stimuli on hotel customer emotional loyalty response: Testing the moderating effect of the big five personality factors. International Journal of Hospitality Management, 44, 48-57.

Jaruwachirathanakul, B., \& Fink, D. (2005). Internet banking adoption strategies for a developing country: The case of Thailand. Internet Research, 15(3), 295-311.

Kaur, H., \& Soch, H. (2012). Validating antecedents of customer loyalty for Indian cell phone users. Vikalpa, 37(4), 47-62.

Kumar, V. R., Lall, A., \& Mane, T. (2017). Extending the TAM model: Intention of management students to use mobile banking: Evidence from India. Global Business Review, 18(1), 238-249.

Lai, S. L., Pham, H.-H., \& Le, A.-V. (2019). Toward Sustainable Overseas Mobility of Vietnamese Students: Understanding Determinants of Attitudinal and Behavioral Loyalty in Students of Higher Education. Sustainability, 11(2), 383. https://doi. org/10.3390/su11020383

Lazim, D., Shah, Z. A., Saedudin, R. R., Kasim, S., Azadin, A. A., Hidayat, R., \& Ansari Saleh Ahmar, I. A. (2018). Information Management and PSM Evaluation System. International Journal of Engineering and Technology, 7(1.6), 17-19.

Le, H. B. H., Ngo, C. T., Trinh, T. T. H., \& Nguyen, T. T. P. (2020). Factor Affecting Customers' Decision to Use Mobile Banking Service: A Case of Thanh Hoa Province, Vietnam. Journal of Asian Finance, Economics and Business, 7(2), 205-212. https://doi.org/10.13106/jafeb.2020.vol7.no2.205 
Makanyeza, C. (2017). Determinants of consumers' intention to adopt mobile banking services in Zimbabwe. International Journal of Bank Marketing, 35(6), 997-1017.

Muchran, M., \& Ahmar, A. S. (2019). Application of TAM model to the use of information technology. arXiv preprint arXiv:1901.11358.

Nguyen, H. Q., \& Le, O. T. T. (2020). Factors Affecting the Intention to Apply Management Accounting in Enterprises in Vietnam. Journal of Asian Finance, Economics, and Business, 7(6), 95107. https://doi.org/10.13106/jafeb.2020.vol7.no6.095

Nunnally, J. C., \& Bernstein, I. (1994). The assessment of reliability. Psychometric Theory, 3(1), 248-292.

Oliver, R. L. (2014). Satisfaction: A behavioral perspective on the consumer: A behavioral perspective on the consumer. London, UK: Routledge.

Park, E., Lim, J., \& Cho, Y. (2018). Understanding the Emergence and Social Acceptance of Electric Vehicles as Next-Generation Models for the Automobile Industry. Sustainability, 10(3), 662. https://doi.org/10.3390/su10030662

Phan, D. T. T., Nguyen, T. T. H., \& Bui, T. A. (2019). Going beyond Border? Intention to Use International Bank Cards in Vietnam. Journal of Asian Finance, Economics and Business, 6(3), 315325. https://doi.org/10.13106/jafeb.2019.vol6.no3.315

Sharma, S. K., Govindaluri, S. M., Al-Muharrami, S., \& Tarhini, A. (2017). A multi-analytical model for mobile banking adoption:
A developing country perspective. Review of International Business and Strategy, 27(1), 133-148.

Singh, S., \& Srivastava, R. (2018). Predicting the intention to use mobile banking in India. International Journal of Bank Marketing, 36(2), 357-378.

Sripalawat, J., Thongmak, M., \& Ngramyarn, A. (2011). M-banking in metropolitan Bangkok and a comparison with other countries. Journal of Computer Information Systems, 51(3), 67-76.

Steenkamp, J. B. E., \& Gielens, K. (2003). Consumer and market drivers of the trial probability of new consumer packaged goods. Journal of Consumer Research, 30(3), 368-384.

Venkatesh, V., Morris, M. G., Davis, G. B., \& Davis, F. D. (2003). User acceptance of information technology: Toward a unified view. MIS Quarterly, 27(3), 425-478. DOI: $10.2307 / 30036540$

Venkatesh, V., \& Zhang, X. (2010). Unified theory of acceptance and use of technology: US vs. China. Journal of Global Information Technology Management, 13(1), 5-27.

Wong, K. K.-K. (2013). Partial least squares structural equation modeling (PLS-SEM) techniques using SmartPLS. Marketing Bulletin, 24(1), 1-32.

Yu, Y., Yi, W., Feng, Y., \& Liu, J. (2018). Understanding the Intention to Use Commercial Bike-sharing Systems: An Integration of TAM and TPB. In: Proceedings of the 51st Hawaii International Conference on System Sciences. 